\title{
DOJO 'GO: Uma Forma Divertida e Colaborativa de se Aprender através de Dojo de Programação de Jogos
}

\author{
Ângelo Magno de Jesus ${ }^{1}$, Gislaine Moura da Silva ${ }^{1}$ \\ ${ }^{1}$ Instituto Federal de Minas Gerais, campus Ouro Branco \\ Rua Afonso Sardinha, 90 - Pioneiros - Ouro Branco / MG CEP: 36420-000 \\ angelo.jesusdifmg.edu.br, gismouralaine@hotmail.com
}

\begin{abstract}
This paper presents the DoJo'Go, a code dojo based methodology to learning programming in order to estimate the Computational Thinking. This paper also describes a report about the experience of using DoJo'Go. The proposed methodology uses game development, on a collaborative way, in order to make a fun and engagement learning experience to high and elementary schools students. The preliminary results shown to be promising, since it was noticed students `engagement during the DoJo'Go `s activities.
\end{abstract}

Resumo. Este artigo apresenta o DoJo'Go, uma metodologia baseada no dojo de código, para aprendizado de programação e estímulo do Pensamento Computacional, assim como descreve um relato de experiência de sua aplicação. A metodologia proposta utiliza o desenvolvimento de jogos de forma colaborativa para tornar a experiência de aprendizado lúdica e atrativa para os estudantes do ensino básico e médio. Os resultados preliminares se mostraram promissores, uma vez que foi notado engajamento dos estudantes durante a atividade realizada com o DoJo'Go.

\section{Introdução}

Aprender Lógica de Programação e o Pensamento Computacional, que a envolve, pode trazer grandes benefícios para crianças e jovens de diferentes idades. Através da prática do Pensamento Computacional jovens e crianças podem aprender a resolver problemas de maneira sistemática e a utilizar a criatividade. Segundo Wing (2006), o Pensamento Computacional é uma habilidade fundamental para todos, e não apenas para cientistas da computação, pois é definido como a capacidade de utilizar abstração e composição para resolver problemas complexos. O Pensamento Computacional pode contribuir para melhorar a capacidade analítica de crianças nas atividades de leitura, escrita e aritmética. No entanto, ainda existem grandes desafios para se incluir atividades relacionadas ao aprendizado de computação em escolas de ensino fundamental e médio. Este artigo apresenta um novo método $D o J o^{\prime} G o$ : Dojo de Programação de Jogos, assim como, um relato de uma experiência inicial de sua aplicação. $\mathrm{O}$ método proposto envolve a construção colaborativa de jogos, por parte dos alunos, que devem utilizar raciocínio lógico, sistematização, criatividade e experimentação para alcançar o objetivo de se concluir o jogo almejado.

O $D o J o^{\prime} G o$ é baseada no Dojo de Código, uma prática de aprendizado de programação, comumente utilizada pela comunidade de desenvolvedores de software nas metodologias Ágeis. Segundo Sato et al. (2008, p.1): 
O Dojo de código é uma atividade onde um grupo de participantes deve resolver uma tarefa de programação em conjunto, utilizando o desenvolvimento orientado a testes e programação em pares. Coding Dojo é uma forma de aprendizagem que valoriza a experiência concreta em um contexto realista.

Além do uso do Dojo de Código, a metodologia proposta neste trabalho utiliza do desenvolvimento de jogos digitais para deixar a atividade ainda mais atrativa e interessante para jovens estudantes. A partir do desenvolvimento de jogos os alunos podem ver o resultado de seus algoritmos através de gráficos animados e, ainda, interagir e se divertir com este resultado. Os dispositivos móveis, principalmente smartphones, são cada vez mais populares entre as crianças, adolescentes e jovens. Portanto, a experiência realizada também levou em consideração a utilização de dispositivos móveis para execução do jogo digital desenvolvido. As aplicações do DoJo'Go tem mostrado resultados promissores.

\section{Trabalhos Relacionados}

Entre os trabalhos relacionados, é importante ressaltar que o Dojo é utilizado como metodologia de ensino predominantemente em cursos de graduação, enquanto existem vários esforços nos níveis de ensino mais básicos para estimular o ensino de computação através do desenvolvimento de jogos. Luz e Neto (2012) apresentam uma experiência, e os benefícios obtidos, de aplicação do Dojo de programação, para o ensino de desenvolvimento dirigido por testes, entre grupos de alunos de graduação. Carmo e Braganholo (2012) propõem o uso didático do Dojo de programação. Os autores idealizam diferentes dinâmicas de aulas que foram aplicadas no decorrer das disciplinas de Algoritmos e Estrutura de Dados de um curso de graduação. Shimohara e Sobreira (2015) descrevem a experiência realizada com turmas do ensino fundamental, na qual os alunos desenvolveram jogos digitais com o objetivo de aprender matemática através de desafios. de Jesus et al. (2014) utilizam o desenvolvimento de jogos digitais, através de metodologias ágeis, para motivar o aprendizado de alunos de diferentes níveis de ensino. Rodriguez et al. (2015), relatam uma experiência realizada com alunos do primeiro ano do ensino médio de uma escola pública, cujo objetivo era desenvolver noções básicas do pensamento computacional através da programação de jogos por meio dos recursos do Scratch. von Wangenheim et al. (2014) descrevem um estudo de caso de ensino de Computação com scratch no ensino fundamental também visando estimular o pensamento computacional através da criação de animações interativas. Este trabalho se diferencia dos demais, por propor uma metodologia que mescla o uso do Dojo com desenvolvimento de jogos digitais. Também é importante observar que a experiência realizada levou em consideração o uso de dispositivos móveis por parte dos alunos.

\section{Método Proposto e Experiência de Aplicação}

É importante ressaltar que a metodologia foi proposta para a realidade brasileira, na qual, normalmente, tem-se turmas com 40 alunos, e laboratórios de Informática com capacidade inferior a este número. O $D o J o^{\prime} G o$, propõe a divisão da atividade em turmas de no máximo 20 alunos. A metodologia proposta segue a seguinte estrutura de 
organização: (1) O professor que aplicará atividade fará o papel de líder técnico; (2) Uma pessoa que deverá ter o conhecimento técnico sobre a tecnologia utilizada na atividade deverá fazer o papel de vice-líder; (3) Os alunos devem se organizar em duplas ou no máximo em trios e cada dupla deverá ter disponível apenas um computador; (4) Na parte da frente do laboratório, um computador principal deve ser preparado, com um projetor para todos verem o que está sendo feito.

Em resumo, a metodologia deverá ser aplicada da seguinte forma:

1) Contextualização: (1.1) $O$ líder técnico inicia a atividade apresentando $o$ ambiente de programação e os recursos disponíveis; (1.2) O líder deve mostrar e explicar o Jogo já implementado e funcionando, que deverá ser o objetivo do Dojo. Ele pode pedir para alguns alunos interagirem, jogando, para estimular a curiosidade dos demais; (1.3) O líder deverá iniciar a preparação do ambiente, adicionando e explicando os objetos que serão utilizados na construção do aplicativo. Nesta etapa, o cenário é construído.

2) Ação: (2.1) Os alunos serão questionados sobre uma funcionalidade para ser implementada no jogo. Nesta etapa, as respostas serão analisadas e deve ser selecionada uma proposta viável de implementação; (2.2) Os estudantes devem eleger dois alunos, preferencialmente de duplas diferentes, para serem piloto e copiloto da implementação; (2.3) O piloto e copiloto vão tentar implementar uma solução, com a ajuda dos demais alunos, que poderão se manifestar livremente com ajuda do líder; (2.4) Assim que a implementação terminar, o teste do aplicativo deverá ser feito, onde piloto e copiloto poderão "jogar" a funcionalidade que foi implementada; (2.5) Se o teste mostrou que a programação foi bem sucedida, deve-se retornar para a etapa 2.1, caso contrário, devese retornar para a etapa 2.2 para solucionar o erro detectado.

3) Finalização: Se o jogo foi finalizado ou se o tempo da atividade se esgotou, cada aluno poderá executar seu aplicativo e se divertir com ele, para posteriormente sugerir melhorias ou novos jogos para uma possível nova atividade.

Devido a limitações de tempo e para tornar a atividade didática, o artefato a ser desenvolvido durante o dojo deve ser planejado como um aplicativo simples. Recomenda-se também enquadrar o artefato na categoria dos jogos casuais, que envolvem um grande público heterogêneo e desta forma podem interessar a todos os alunos. A implementação deve levar em consideração a separação em diferentes desafios lógicos que podem ser resolvidos em sequência progressiva, mas de forma independente, como por exemplo: (1) fazer um objeto se movimentar na tela, (2) usuário interagir com objetos, (3) somar pontos etc. Esta sequência de desafios estimula o pensamento computacional por contemplar a divisão de um problema maior em subproblemas menos complexos que devem ser resolvidos passo a passo através de estratégias de lógica.

Em nossos experimentos, foi utilizado como tecnologia de implementação o ambiente AppInventor (2016) para aplicação no ensino médio. O AppInventor foi escolhido por permitir a criação de jogos, de maneira prática e fácil, para dispositivos móveis Android que são populares entre adolescentes no ensino médio. 
V Congresso Brasileiro de Informática na Educação (CBIE 2016)

Anais do XXII Workshop de Informática na Escola (WIE 2016)

Foi realizada uma experiência com alunos do segundo ano do ensino médio técnico em Informática do Instituto Federal de Minas Gerais campus Ouro Branco. A turma possuía cerca de 35 alunos e foi dividida em duas subturmas para se aplicar a metodologia. O jogo proposto foi batizado de Tomates Loucos. No aplicativo, vários tomates aparecerão aleatoriamente na tela do aparelho, por alguns segundos, e desaparecerão. O jogador deverá amassar o maior número de tomates que for capaz, tentando tocá-los o mais rápido possível. A cada tomate amassado o usuário ganha um ponto. Como recomenda a metodologia, esta implementação pode ser dividida nos seguintes desafios lógicos: (1) fazer os tomates se movimentarem aleatoriamente na tela, (2) fazer os tomates amassarem ao serem tocados pelo usuário e (3) somar pontos. A Figura 1 (A) mostra o jogo desenvolvido pelos alunos. A Figura 1 (B) ilustra uma parte da implementação feita durante a experiência.

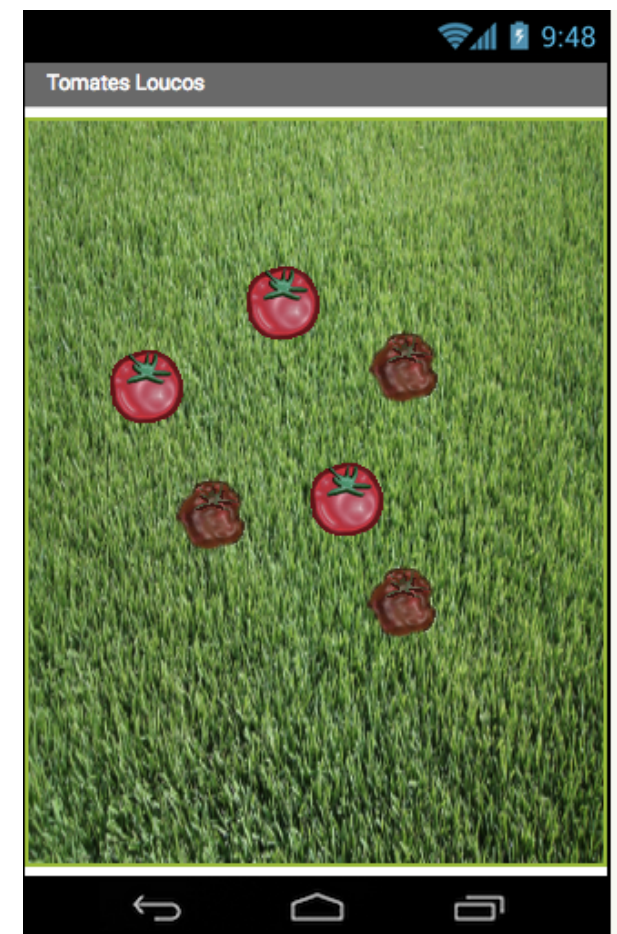

(A)

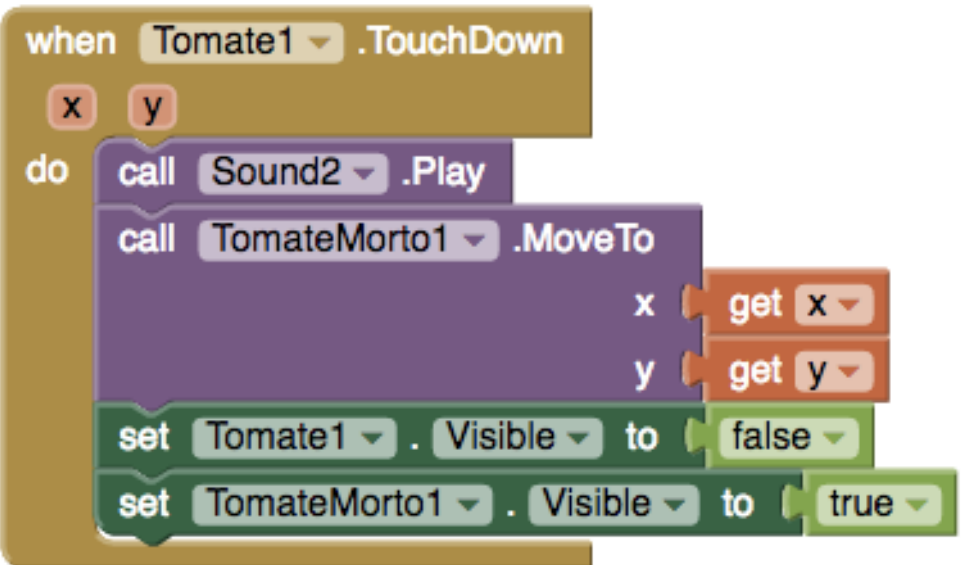

(B)

Figura 1: (A) Tela do jogo "Tomates Loucos" desenvolvido pelos alunos durante o Dojo; (B) Parte de uma funcionalidade do jogo implementada durante o Dojo.

\section{Resultados e Discussão}

A atividade levou cerca de 100 minutos para ser concluída por cada turma. A experiência se mostrou bem sucedida. Ao final da experiência, os alunos puderam instalar os jogos em seus celulares, para se entreterem e interagirem com o produto do trabalho do grupo. Foram observados entre os alunos: Engajamento, os alunos estavam interessados em resolver os problemas propostos explorando os recursos do AppInventor; Atenção: os alunos estavam atentos aos passos dados pelo piloto e copiloto; Colaboração: os alunos sempre se colocavam a disposição para auxiliar os 
V Congresso Brasileiro de Informática na Educação (CBIE 2016)

Anais do XXII Workshop de Informática na Escola (WIE 2016)

pilotos na solução das questões; Diversão: ao serem realizados os testes os alunos interagiam e se divertiam com os resultados.

\section{Conclusões e Trabalhos Futuros}

O $D o J o^{\prime} G o$ tem-se mostrado uma metodologia que pode estimular o pensamento computacional de forma lúdica e colaborativa. Como trabalho futuro, pretende-se ampliar a prática da metodologia em diferentes turmas do ensino básico de várias escolas públicas. Para aplicação no ensino fundamental, um jogo está sendo preparado no ambiente Scratch (2015), tecnologia que vem contribuir para construção de um ensino de Programação de maneira lúdica e pode ser utilizado facilmente por crianças.

\section{Referências}

AppInventor (2016) http://appinventor.mit.edu/explore/, Março.

Carmo, D. H. e Braganholo, V. (2012) "Um Estudo sobre o Uso Didático de DOJOs de Programação". In: Anais do XXXII Congresso da Sociedade Brasileira de Computação (CSBC 2012).

de Jesus, A. M.; Gonçalves, D. A. S. e Ferreira, L. A. C. (2014). In: Anais do 20 Workshop de Informática na Escola (WIE 2014).

Luz, R. B. e Neto, A. (2012) "Usando Dojos de Programação para o Ensino de Desenvolvimento Dirigido por Testes". In: Anais do $23^{\circ}$ Simpósio Brasileiro de Informática na Educação (SBIE 2012), ISSN 2316-6533.

Rodriguez, C. L.; Zem-Lopes, A. M., Marques, L. e Isotani, S. (2015) "Pensamento Computacional: transformando ideias em jogos digitais usando o Scratch". In: Anais do XXI Workshop de Informática na Escola (WIE 2015).

Sato, D. T., Corbucci, H. and Bravo, M. (2008) "Coding Dojo: an environment for learning and sharing agile practices". In Proceedings of the Agile 2008. IEEE Computer Society. http://dx.doi.org/10.1109/Agile.2008.11.

Scratch (2015) https://scratch.mit.edu/, Novembro.

Shimohara, C. e Sobreira, E. S. R. (2015) "Criando Jogos Digitais para a Aprendizagem de Matemática no Ensino Fundamental I". In: Anais do XXI Workshop de Informática na Escola (WIE 2015) .

von Wangenheim, C. G.; Nunes, V. R. e dos Santos, G. D. (2014) "Ensino de Computação com SCRATCH no Ensino Fundamental - Um Estudo de Caso". Revista Brasileira de Informática na Educação, Volum

Wing, J. M. (2006). "Computational thinking. Commun". ACM, 49(3):33-35. 